\title{
Urinary function following radical cystectomy and orthotopic neobladder urinary reconstruction
}

Ameeta L. Nayak; Ilias Cagiannos; Luke T. Lavallée; Chris Morash; Duane Hickling; Ranjeeta Mallick; Rodney H. Breau

Division of Urology, Department of Surgery, University of Ottawa and The Ottawa Hospital Research Institute; Ottawa, ON, Canada

Cite as: Can Urol Assoc J 2018 Feb. 23; Epub ahead of print. http://dx.doi.org/10.5489/cuaj.4877

Published online February 23, 2018

$* * *$

\section{Abstract}

Introduction: An orthotopic neobladder urinary diversion aims to minimize the physical and psychological effects of radical cystectomy through avoidance of a stoma and maintenance of urethral voiding. Neobladder function reported in the literature ranges widely due to differences in patient selection and method of assessment. The objective of the study was to characterize functional outcomes of consecutive patients treated at a tertiary care hospital.

Methods: A historical cohort of patients who underwent radical cystectomy with a neobladder diversion performed at The Ottawa Hospital between January 2006 and December 2014 were reviewed. Outcomes of interest were urinary continence, use of intermittent catheterization, postvoid residual volume, and uroflowmetry at three, six, and 12 months following cystectomy. Results: During the study period, 158 neobladder diversions were performed. The mean age of patients was 63.1 years (standard deviation [SD] 8.1), and 81.7\% were male. Significant daytime incontinence ( $>1$ pad) three months following surgery was common (65\%), but decreased to $8.6 \%$ by 12 months. Nighttime incontinence was also common at three months (54\%) and improved at 12 months (20\%). While no appreciable differences between men and women were observed for continence, more women performed intermittent catheterization at 12 months postsurgery (59\% of women; $9 \%$ of men; relative risk [RR] 0.15; 95\% confidence interval [CI] 0.070.30). Among patients who did not catheterize, uroflowmetry and post-void residual volume parameters were stable between three and 12 months postoperative.

Conclusions: Daytime and nighttime incontinence is common in neobladder patients following surgery, but improves considerably with time. Correspondingly, many female neobladder patients at our institution use intermittent catheterization. 


\section{Introduction}

Bladder cancer is the fifth most common cancer in Canada. Approximately 8,300 Canadians are diagnosed with bladder cancer annually, and 2,300 die from the disease yearly. ${ }^{1}$ Approximately one third of patients with non-metastatic bladder cancer develop muscle invasive disease, ${ }^{2}$ where neoadjuvant chemotherapy and radical cystectomy remains a standard of care. ${ }^{3,4}$

Maintaining quality of life following radical cystectomy is an important consideration when choosing the method of urinary diversion. While an ileal conduit is the traditional form of urinary diversion, an orthotopic continent diversion (neobladder) is preferred by some patients with an aim to achieve a better post-operative quality of life. ${ }^{5-9}$ Creation of a neobladder allows patients to avoid a stoma and permits urethral voiding. ${ }^{10}$ Patients who receive a neobladder often have better physical function and improved psychological well-being compared to patients with an ileal conduit. ${ }^{9-11}$ Neobladders ideally function as a continent reservoir that allows for efficient urethral emptying. However, patients must be aware of the potential for both incontinence and urinary retention. ${ }^{12}$ Currently, an accurate expectation of neobladder function is limited because studies have reported vast differences in risk. For example, the prevalence of complete day and night continence one year following surgery has been reported as low as $22 \%$ and as high as $63 \% .^{13}$

To adequately counsel patients, accurate data are needed to characterize post-operative function and adverse events of each type of diversion. In the United States, $20 \%$ of patients receive a continent urinary diversion, ${ }^{14}$ with high case-volume hospitals performing a higher proportion of continent diversion compared to low case-volume hospitals. ${ }^{15}$ It is possible that some centers offer neobladders only to the healthiest patients and achieve superior functional outcomes compared to centers who endorse more liberal eligibility criteria. The purpose of this study was to evaluate the functional outcomes in patients receiving orthotopic neobladders at The Ottawa Hospital where approximately 50\% of patients receive this form of lower urinary tract reconstruction.

\section{Methods}

After institutional research ethics board approval, a historical cohort study was conducted with consecutive patients from The Ottawa Hospital who underwent an open radical cystectomy with neobladder diversion from January 2006 to December 2014. All neobladders were created by surgeons who had fellowship training in urological oncology. At our center, continent diversion options are presented to all patients without medical contraindications. While no strict eligibility criteria are used, in general, neobladder diversion is advocated for patients with good physical, cognitive, and renal function. Alternative forms of diversion (ileal conduit or continent catheterizable pouches) are offered to patients who are not neobladder candidates due to other medical conditions (e.g. renal dysfunction), pre-existing urinary incontinence, urethral strictures, or anterior urethral tumours. 
Medical records were reviewed to capture baseline patient and tumour information. In all cases, a orthotopic neobladder (Studer method) was created with ureteral stents tethered to a 24-French urethral catheter. Ureteral stents were not routinely externalized nor were suprapubic catheters routinely used. Patients received similar perioperative care based on a standardized institutional care pathway. The urethral catheter and ureteral stents were removed 3 weeks following surgery. Neobladder patients participate in teaching sessions and are taught to void using Credé's manoeuvre every hour during the day, extending the interval between voids by ten minutes every week until they reach 3 hours between each voiding attempt. At night, patients were counselled to wake at least once to empty their neobladder.

\section{Post-operative assessments}

Post-operative neobladder function was assessed and documented during follow-up clinic visits. In general, patients were followed at least 3, 6, and 12 months following surgery with further follow-up based on the intensity of cancer surveillance required. At each assessment, patients were asked to characterize their daytime and nighttime urinary function including; use of incontinence products. If incontinence products (pads) were used, patients were asked how many pads they used, regardless of type of pad or how saturated they became. The use of intermittent catheterization was documented. In general, intermittent catheterization is recommended at our center when patients have complete urinary retention or if they have partial urinary retention and secondary signs and symptoms of retention (e.g.persistent urinary tract infection, overflow incontinence, or worsening renal function). Uroflowmetry and post-void residual volume via bladder ultrasound was performed by clinic nurses and documented in the medical record. Using a standardized data collection form, severity of incontinence during the day and night was categorized as: fully continent (no use of pads); mild incontinence (1 pad per day or night); or incontinent ( 2 or more pads per day or night). Peak urinary flow, mean urinary flow, and postvoid residual urine volume was abstracted. For all time points, the closest pre-defined period was used. For example, if a patient was seen in follow-up 2 months or 4 months post-operative, the corresponding data was used to populate the 3-month post-surgery outcomes. If a patient was not assessed, that time point was documented as “missing”. For patients who died during follow-up, functional information prior to their death was used and was censored after death.

\section{Analysis}

Given previous reports of differences in neobladder function between men and women, information was summarized and tabulated stratified by sex. Patient reported continence, uroflowmetry characteristics, and post-void residual volume were presented for each postoperative time point. Univariable analysis was performed using t-tests or chi-squared tests as appropriate. No correction was made for multiple testing and $\mathrm{p} \leq 0.05$ was considered statistically significant. Analyses were performed using SAS (SAS Institute Inc., Cary, NC, U.S.). 


\section{Results}

\section{Cohort characteristics}

A total of 158 patients underwent a radical cystectomy with neobladder diversion from 20062014. Mean patient age at surgery was 63.1 years (SD 8.41), and the majority of patients were male (81.7\%). Baseline characteristics of the cohort are presented in Table 1. Prior to cystectomy, there were no differences in baseline characteristics between male and female patients, with the exception of more men receiving neoadjuvant chemotherapy. Nine patients had prior pelvic radiation (5 had previous chemoradiation to the bladder with curative intent, 3 received radiation for conditions other than bladder cancer, and 1 received palliative radiation for recalcitrant hematuria). Less than $10 \%$ of patients reported urinary incontinence prior to surgery. In all cases, pre-operative incontinence was described by patients as mild, or attributed to severe cancer related bladder overactivity.

Neobladder functional data were not available for 17 patients at follow up for the following reasons: 5 died before the 3 month follow up, 7 patients had cancer progression and were followed by medical oncology where functional data was not captured, 4 patients were lost to follow-up, and 1 patient was converted to an ileal conduit 4 weeks post-neobladder creation due to multiple medical conditions and complications, including wound and neobladder dehiscence.

\section{Functional outcomes}

Daytime and nighttime incontinence was common in the early post-operative period, but decreased substantially over time. By one year follow-up, approximately $70 \%$ of men and women did not use pads in the daytime and less than $10 \%$ used more than 1 pad per day (Table 2). Long-term nighttime incontinence was more prevalent with $60 \%$ requiring pads at night and $25 \%$ using more than 1 pad per night. While risk of incontinence was similar between men and woman, a larger proportion of women used intermittent catheterization. At one year postsurgery, $59 \%$ of women used CIC, compared to $9 \%$ of men (Table 2).

Uroflowmetry measurements and post-void residual volumes are presented in Table 3. Urine flow parameters did not change during follow-up. Women had higher flow rates, but this difference was not statistically significant. Median post-void residual volumes of patients who did not catheterize increased slightly over time, from 14cc [IQR 0-60cc] to 31cc [IQR 0-87cc]. At one year follow-up, there were significantly more women with high residual volumes using CIC.

Associations between patient characteristics and neobladder function

With the exception of sex, few baseline parameters were associated with neobladder function. In some cases, clinically significant associations were observed, but the cohort was underpowered to determine if the findings were due to chance. Patients who received neoadjuvant 
chemotherapy were more likely to experience daytime incontinence (RR 1.55, 95\% CI 0.85-2.85, $\mathrm{p}=0.15$ ). Nighttime incontinence was more common in patients with diabetes (RR 1.41, 95\% CI 1.04-1.91, $\mathrm{p}=0.03$ ). While not statistically significant, older patients were more likely to experience daytime and nighttime incontinence (Table 4). Patients with a smoking history were more likely to perform CIC (RR 2.31, 95\% CI 0.91-5.87, p=0.08), as did older women (Table 4). Patients who received chemotherapy were less likely to require CIC (RR 0.31, 95\% CI 0.091.85, $\mathrm{p}=0.24$ ), however none of these associations were statistically significant.

\section{Discussion}

An orthotopic neobladder is an established urinary diversion option for patients who require a radical cystectomy. At our center we have adopted fairly liberal eligibility criteria for neobladder and approximately 50\% of patients choose a neobladder diversion. These data show that most patients experience acceptable functional outcomes. Daytime and nighttime incontinence in neobladder patients is common following surgery but improves considerably over time. By one year post-radical cystectomy, $71 \%$ and $40 \%$ use no pads during the day and night, respectively. Using current selection practices, it was found that continence was similar between men and women. Conversely, over time, the use of intermittent catheterization increases following surgery, especially in women.

Previous publications report continence is achieved in $85-100 \%$ of patients during the day, and between 60-95\% at night. ${ }^{11,16}$ However, there have been reports of an even wider range of continence, with some overall continence rates as low as $18 \%$ and as high as $92 \%$ at follow-up periods beyond 1 year. ${ }^{17,18}$ The definition of continence differs between studies, and variations in patient reporting makes it difficult to compare continence outcomes among institutions. For example, in this cohort, $20 \%$ of patients used 1 pad during the day and $40 \%$ used 1 pad at night. Often, the pad was described by patients as a "security pad" because of rare and minor incontinence. Similarly, Ahmadi et al. reported $47 \%$ of patients use at least 1 pad during the day and $72 \%$ wear pads at night, but $47 \%$ of pad users were essentially dry. ${ }^{19}$ It is clear that pad use may not always reflect the level of continence or patient satisfaction. A complete representation of patient continence should include not only number of pads, but also size of pads, degree of wetness, frequency of incontinence episodes, and most importantly, patient bother. There is a need for a validated neobladder specific patient reported outcome instrument to help inform future patients and to compare between surgical techniques.

Nighttime incontinence is more prevalent than daytime incontinence for both men and women. This difference is thought to be due to the absence of a "guarding" reflex, increased dwell time of concentrated urine that is diluted via osmosis through the neobladder mucosa, and potentially due to increased nocturnal urine production. ${ }^{20}$ We observed that patients with diabetes have an increased risk of nighttime incontinence, consistent with previous publications. ${ }^{19,21}$ It has been hypothesized that diabetic neuropathy may affect autonomic 
innervation of the urethral sphincter and urethral sensation has been suggested to contribute to incontinence. $^{21}$

We observed that partial or complete urinary retention increased over time. In the present study, more than half of women were self-catheterizing by one year following surgery. The proportion of patients in this study using CIC is at the upper end of what is reported in the literature. $^{22-25}$ Differences between institutions may be due to our routine use of post-void ultrasound and liberal recommendation of CIC for patients who do not completely empty their neobladder and have other symptoms, such as incontinence. It has been our observation that patients with retention have more incontinence episodes, which improves with the use of CIC. Many of our patients report better quality of life with CIC to avoid incontinence. Certainly, chronic urinary retention following neobladder diversion in women is prevalent, and women considering neobladder construction should be informed about the strong possibility of intermittent catheterization.

There are several potential limitations to this study that should be considered when interpreting the results. Since this was a retrospective review, the timing of follow up was not consistent for every patient and some patients had incomplete documentation of uroflow, postvoid residual volume, or urinary function. Methods to document urinary function were consistent but were not based on validated instruments. Associations between baseline patient characteristics and post-operative urinary function were limited due to a relatively small sample size. Despite these limitations, we have reported the functional outcomes of a reasonably large cohort. We have shown that continent urinary diversion is feasible in a substantial proportion of radical cystectomy patients with acceptable urinary function for most patients. Future prospective studies with validated and standardized outcome measures will be helpful to improve the precision of post-operative estimates of function.

\section{Conclusion}

Daytime and nighttime continence in neobladder patients improves during the first year following surgery. Correspondingly, post-void residual volumes increase and many female neobladder patients at our institution use intermittent catheterization to avoid incontinence and prevent complications of retention. Goals of neobladder diversion include avoidance of a stoma, maintenance of continence, and urethral voiding. While some of these goals are frequently achieved, patients should be provided with detailed information to help them make an educated decision regarding treatment preferences. 


\section{References}

1. Advisory committee on cancer statistics. Canadian Cancer Statistics 2015. Toronto, ON: Canadian cancer society; 2015.

2. Sternberg CN. Muscle invasive and metastatic bladder cancer. Ann Oncol 2006;17:S23S30.

3. Hsu T, Black PC, Chi KN, et al. Treatment of muscle-invasive bladder cancer in Canada: a survey of genitourinary medical oncologists and urologists. Can Urol Assoc $J$ 2014;8:309-16.

4. Yafi FA, Kassouf W. Radical cystectomy is the treatment of choice for invasive bladder cancer. Can Urol Assoc J 2009;3:409-12.

5. Ghosh A, Somani BK. Recent trends in postcystectomy health-related quality of life (QoL) favors neobladder diversion: systematic review of the literature. Urology 2016;93:22-6.

6. Cerruto MA, D’Elia C, Siracusano S, et al. Systematic review and meta-analysis of non RCT's on health related quality of life after radical cystectomy using validated questionnaires: better results with orthotopic neobladder versus ileal conduit. Eur J Surg Oncol 2016;42:343-60.

7. Hobisch A, Tosun K, Kinzl J, et al. Life after cystectomy and orthotopic neobladder versus ileal conduit urinary diversion. Semin Urol Oncol 2001;19:18-23.

8. Bjerre BD, Johansen C, Steven K. Health-related quality of life after cystectomy: bladder substitution compared with ileal conduit diversion. A questionnaire survey. Br J Urol 1995;75:200-5.

9. Philip J, Manikandan R, Venugopal S, et al. Orthotopic neobladder versus ileal conduit urinary diversion after cystectomy - A quality-of-life based comparison. Ann R Coll Surg Engl 2009;91:565-9.

10. Meyer JP, Blick C, Arumainayagam N, et al. A three-centre experience of orthotopic neobladder reconstruction after radical cystectomy: revisiting the initial experience, and results in 104 patients. BJU Int 2009;103:680-3.

11. Lee RK, Abol-Enein H, Artibani W, et al. Urinary diversion after radical cystectomy for bladder cancer: options, patient selection, and outcomes. BJU Int 2014;113:11-23.

12. Goldberg H, Baniel J, Mano R, et al. Orthotopic neobladder vs. ileal conduit urinary diversion: a long-term quality-of-life comparison. Urol Oncol 2016;34:121.e1-121.e7.

13. Chang DT, Lawrentschuk N. Orthotopic neobladder reconstruction. Urol Ann 2015;7:1-7.

14. Gore JL, Saigal CS, Hanley JM, et al. Variations in reconstruction after radical cystectomy. Cancer 2006;107:729-37.

15. Hollenbeck BK, Wei Y, Birkmeyer JD. Volume, process of care, and operative mortality for cystectomy for bladder cancer. Urology 2007;69:871-5. 
16. Hautmann RE, Abol-Enein H, Davidsson T, et al. ICUD-EAU international consultation on bladder cancer 2012: Urinary diversion. Eur Urol 2013;63:67-80.

17. Novara G, Ficarra V, Minja A, et al. Functional results following Vescica Ileale Padovana (VIP) neobladder: midterm follow-up analysis with validated questionnaires. Eur Urol 2010;57:1045-51.

18. Koie T, Hatakeyama S, Yoneyama T, et al. Experience and functional outcome of modified ileal neobladder in 95 patients. Int J Urol 2006;13:1175-9.

19. Ahmadi H, Skinner EC, Simma-Chiang V, et al. Urinary functional outcome following radical cystoprostatectomy and ileal neobladder reconstruction in male patients. $J$ Urol 2013;189:1782-8.

20. El Bahnasawy MS, Osman Y, Gomha MA, et al. Nocturnal enuresis in men with an orthotopic ileal reservoir: urodynamic evaluation. J Urol 2000;164:10-3.

21. Kessler TM, Ochsner K, Studer UE, et al. Diabetes mellitus: does it impair urinary continence after radical cystoprostatectomy and ileal orthotopic bladder substitution? Eur Urol 2008;53:1040-6.

22. Hautmann RE, de Petriconi R, Gottfried HW, et al. The ileal neobladder: complications and functional results in 363 patients after 11 years of followup. $J$ Urol 1999;161:422-8.

23. Skolarikos A, Deliveliotis C, Alargof E, et al. Modified ileal neobladder for continent urinary diversion: functional results after 9 years of experience. $J$ Urol 2004;171:2298301.

24. Miyake H, Furukawa J, Takenaka A, et al. Long-term functional outcomes in patients with various types of orthotopic intestinal neobladder. Int J Urol 2008;15:612-5.

25. Granberg CF, Boorjian SA, Crispen PL, et al. Functional and oncological outcomes after orthotopic neobladder reconstruction in women. BJU Int 2008;102:1551-5. 


\begin{tabular}{|c|c|c|c|c|}
\hline & $\begin{array}{l}\text { Overall } \\
(n=158)\end{array}$ & $\begin{array}{c}\text { Male } \\
(n=129)\end{array}$ & $\begin{array}{l}\text { Female } \\
(n=29)\end{array}$ & $\mathbf{p}$ \\
\hline \multicolumn{5}{|l|}{ Demographics } \\
\hline Age in years, mean (SD) & $63.1(8.4)$ & $62.8(8.8)$ & $64.2(6.6)$ & 0.4 \\
\hline Cardiovascular disease, n (\%) & $35(22.2)$ & $31(24.0)$ & $4(13.8)$ & 0.2 \\
\hline Diabetes mellitus, n (\%) & $21(13.3)$ & $20(15.5)$ & $1(3.5)$ & 0.1 \\
\hline Hypertension, n (\%) & $71(44.9)$ & $56(43.4)$ & $15(51.7)$ & 0.4 \\
\hline Smoking history, n (\%) & $96(61.2)$ & $78(60.9)$ & $18(62.1)$ & 0.9 \\
\hline Neoadjuvant chemotherapy, n (\%) & $30(19.0)$ & $29(22.5)$ & $1(3.5)$ & 0.02 \\
\hline \multicolumn{5}{|c|}{ Pathology characteristics from cystectomy specimen } \\
\hline AJCC T stage, n (\%) & & & & \multirow{4}{*}{0.7} \\
\hline Cis/T0/T1 & $81(52.9)$ & $67(53.2)$ & $14(51.9)$ & \\
\hline $\mathrm{T} 2$ & $43(28.1)$ & $34(27.0)$ & $9(33.3)$ & \\
\hline T3/T4 & $29(19.0)$ & $25(19.8)$ & $4(14.8)$ & \\
\hline \multicolumn{5}{|l|}{ WHO grade, $\mathrm{n}(\%)$} \\
\hline Low & $13(9.4)$ & $11(9.6)$ & $2(8.7)$ & \multirow[t]{2}{*}{1.0} \\
\hline High & $125(90.6)$ & $104(90.4)$ & $21(91.3)$ & \\
\hline \multirow{3}{*}{$\begin{array}{c}\text { Tumour Histology, n (\%) } \\
\text { Urothelial carcinoma } \\
\text { Variant histology }\end{array}$} & & & & \multirow{3}{*}{0.7} \\
\hline & $143(93.5)$ & $116(92.8)$ & $27(96.4)$ & \\
\hline & $10(6.5)$ & $9(7.2)$ & $1(3.6)$ & \\
\hline \multicolumn{5}{|l|}{ Preoperative continence, n (\%) } \\
\hline Continent & $148(93.6)$ & $122(94.6)$ & $26(89.7)$ & 0.4 \\
\hline Occasional incontinence & $10(6.4)$ & $7(5.4)$ & $3(10.3)$ & \\
\hline
\end{tabular}

AJCC T: American Joint Committee on Cancer Tumour stage; Cis: carcinoma in situ; WHO: World Health Organization. 


\begin{tabular}{|c|c|c|c|c|}
\hline & Overall & Male & Female & $\mathbf{p}^{\mathbf{a}}$ \\
\hline Total n & 158 & 129 & 29 & \\
\hline \multicolumn{5}{|c|}{ Daytime incontinence } \\
\hline \multicolumn{5}{|l|}{3 months, $\mathrm{n}(\%)^{\mathrm{b}}$} \\
\hline No pads & $45(34.6)$ & $35(34.0)$ & $10(37.0)$ & 0.9 \\
\hline 1 pad & 44 (33.9) & $36(35.0)$ & $8(29.6)$ & \\
\hline$>1$ pad & $41(31.5)$ & $32(31.0)$ & $9(33.4)$ & \\
\hline Missing & $28(17.7)$ & $26(20.2)$ & $2(6.9)$ & \\
\hline \multicolumn{5}{|l|}{6 months, $\mathrm{n}(\%)^{\mathrm{b}}$} \\
\hline No pads & $58(47.9)$ & $46(47.4)$ & $12(50.0)$ & 0.2 \\
\hline 1 pad & $41(33.9)$ & $36(37.1)$ & $5(20.8)$ & \\
\hline$>1$ pad & $22(18.2)$ & 15 (15.5) & $7(29.2)$ & \\
\hline Missing & $37(23.4)$ & $32(24.8)$ & $5(17.2)$ & \\
\hline \multicolumn{5}{|l|}{$12+$ months, $n(\%)^{b}$} \\
\hline No pads & $83(70.9)$ & $70(71.4)$ & $13(68.4)$ & 0.4 \\
\hline 1 pad & $24(20.5)$ & $21(21.4)$ & $3(15.8)$ & \\
\hline$>1$ pad & $10(8.6)$ & $7(7.2)$ & $3(15.8)$ & \\
\hline Missing & $41(25.9)$ & $31(24.0)$ & $10(34.5)$ & \\
\hline \multicolumn{5}{|c|}{ Night time incontinence } \\
\hline \multicolumn{5}{|l|}{3 months, $n(\%)^{b}$} \\
\hline No pads & $22(16.7)$ & $14(13.3)$ & $8(29.6)$ & 0.1 \\
\hline 1 pad & $39(29.5)$ & $33(31.4)$ & $6(22.2)$ & \\
\hline$>1$ pad & $71(53.8)$ & $59(55.3)$ & $13(48.2)$ & \\
\hline Missing & $26(16.5)$ & $23(17.8)$ & $2(6.9)$ & \\
\hline \multicolumn{5}{|l|}{6 months, $\mathrm{n}(\%)^{\mathrm{b}}$} \\
\hline No pads & $35(29.0)$ & $25(26.0)$ & $10(40.0)$ & 0.2 \\
\hline 1 pad & $43(35.5)$ & $38(39.6)$ & $5(20.0)$ & \\
\hline$>1$ pad & $43(35.5)$ & $33(34.4)$ & $10(40.0)$ & \\
\hline Missing & 37 (23.4) & $33(25.6)$ & $4(13.8)$ & \\
\hline \multicolumn{5}{|l|}{$12+$ months, $\mathrm{n}(\%)^{\mathrm{b}}$} \\
\hline No pads & $48(41.4)$ & $37(38.1)$ & $11(57.8)$ & 0.2 \\
\hline 1 pad & $45(38.8)$ & $41(42.3)$ & $4(21.1)$ & \\
\hline$>1$ pad & $23(19.8)$ & $19(19.6)$ & $4(21.1)$ & \\
\hline Missing & $42(26.6)$ & $32(24.8)$ & $10(34.5)$ & \\
\hline \multicolumn{5}{|c|}{ Intermittent catheterization } \\
\hline 3 months, n (\%) & $7(5.1)$ & $3(2.7)$ & $4(14.8)$ & 0.03 \\
\hline
\end{tabular}




\begin{tabular}{|l|c|c|c|c|}
\hline 6 months, $\mathrm{n}(\%)$ & $10(7.9)$ & $5(5.0)$ & $5(19.2)$ & 0.03 \\
\hline $12+$ months, $\mathrm{n}(\%)$ & $22(17.3)$ & $9(8.6)$ & $13(59.1)$ & $<0.0001$ \\
\hline
\end{tabular}

a $\mathrm{p}$ corresponds to the comparison between male and female. ${ }^{b}$ Proportions for continence status correspond to total number of patients with functional data.

\begin{tabular}{|c|c|c|c|c|}
\hline & Overall & Male & Female & $\mathbf{p}^{\mathbf{a}}$ \\
\hline \multicolumn{5}{|l|}{ Peak flow (cc/s) } \\
\hline 3 months, mean (SD) & $16.1(9.7)$ & $15.3(8.7)$ & $22.1(14.5)$ & 0.2 \\
\hline 6 months, mean (SD) & $17.5(10.3)$ & $16.5(9.5)$ & $23.7(13.4)$ & 0.05 \\
\hline 12 months, mean (SD) & $18.0(12.5)$ & $17.6(12.6)$ & $21.7(11.8)$ & 0.4 \\
\hline \multicolumn{5}{|l|}{ Mean flow (cc/s) } \\
\hline 3 months, mean (SD) & $7.4(3.3)$ & $7.3(3.4)$ & $8.3(2.9)$ & 0.5 \\
\hline 6 months, mean (SD) & $8.6(5.7)$ & $8.0(5.1)$ & $11.4(7.8)$ & 0.1 \\
\hline 12 months, mean (SD) & $7.9(4.8)$ & $7.9(5.0)$ & $8(1.8)$ & 0.9 \\
\hline \multicolumn{5}{|l|}{ Post-void residual volume (cc) } \\
\hline 3 months, median (IQR) & $14(0,60)$ & $17(0,60)$ & $2.5(0,45)$ & 0.4 \\
\hline <100cc, n (\%) & $86(75.4)$ & $71(77.2)$ & $15(68.2)$ & \\
\hline $100 \mathrm{cc}-<500 \mathrm{cc}, \mathrm{n}(\%)$ & $19(16.7)$ & $16(17.4)$ & $3(13.6)$ & 0.2 \\
\hline >500cc or CIC, n (\%) & $9(7.9)$ & $5(5.4)$ & $4(18.2)$ & \\
\hline 6 months, median (IQR) & $20(0.56)$ & $18.5(0.57)$ & $20(0.40)$ & 0.8 \\
\hline <100cc, n (\%) & $75(72.8)$ & $60(74.1)$ & $15(68.2)$ & \\
\hline $100 \mathrm{cc}-<500 \mathrm{cc}, \mathrm{n}(\%)$ & $15(14.6)$ & $13(16.0)$ & $2(9.1)$ & 0.2 \\
\hline >500cc or CIC, n (\%) & $13(12.6)$ & $8(9.9)$ & $5(22.7)$ & \\
\hline 12 months, median (IQR) ${ }^{\mathrm{b}}$ & $31(0.87)$ & $31.5(2.91)$ & $0(0.64)$ & 0.1 \\
\hline <100cc, n (\%) & $79(65.8)$ & 69 (71.9) & $10(41.6)$ & \\
\hline 100 cc-<500cc, n (\%) & $17(14.2)$ & $16(16.7)$ & $1(4.2)$ & $<0.001$ \\
\hline >500cc or CIC, n (\%) & $24(20)$ & $11(11.4)$ & $13(54.2)$ & \\
\hline
\end{tabular}

a $\mathrm{p}$ corresponds to the comparison between male and female. ${ }^{b}$ Median values presented exclude patients who performed CIC. CIC: clean intermittent catheterization; IQR: interquartile range; SD: standard deviation. 


\begin{tabular}{|c|c|c|c|c|c|c|}
\hline \multirow[t]{2}{*}{ Age group } & \multicolumn{3}{|c|}{ Male } & \multicolumn{3}{|c|}{ Female } \\
\hline & No pads & Pads & $\mathbf{p}$ & No pads & Pads & $\mathbf{p}$ \\
\hline $\begin{array}{l}\text { Daytime incontinence, } \\
\mathrm{n}(\%) \\
\text { Age } \leq 60 \\
\text { Age } 60-70 \\
\text { Age } 70-80\end{array}$ & $\begin{array}{c}32(80) \\
29(67.4) \\
9(60)\end{array}$ & $\begin{array}{c}8(20) \\
14(32.6) \\
6(40)\end{array}$ & 0.25 & $\begin{array}{c}4(80) \\
7(58.3) \\
2(100)\end{array}$ & $\begin{array}{c}1(20) \\
5(41.7) \\
0(0)\end{array}$ & 0.47 \\
\hline $\begin{array}{l}\text { Nighttime } \\
\text { incontinence, n (\%) } \\
\text { Age } \leq 60 \\
\text { Age } 60-70 \\
\text { Age } 70-80\end{array}$ & $\begin{array}{c}20(51.3) \\
13(29.6) \\
4(28.6)\end{array}$ & $\begin{array}{l}19(48.7) \\
31(70.5) \\
10(71.4)\end{array}$ & 0.09 & $\begin{array}{c}2(40) \\
7(58.3) \\
2(100)\end{array}$ & $\begin{array}{c}3(60) \\
5(41.7) \\
0(0)\end{array}$ & 0.41 \\
\hline $\begin{array}{l}\text { Intermittent } \\
\text { catheterization, n (\%) } \\
\quad \leq 60 \\
60-70 \\
70-80\end{array}$ & $\begin{array}{c}\text { No CIC } \\
38(90.5) \\
43(89.6) \\
15(100)\end{array}$ & $\begin{array}{c}\text { CIC } \\
4(9.5) \\
5(10.4) \\
0(0)\end{array}$ & 0.57 & $\begin{array}{c}\text { No CIC } \\
4(80) \\
5(33.3) \\
0(0)\end{array}$ & $\begin{array}{c}\text { CIC } \\
1(20) \\
10(66.7) \\
2(100)\end{array}$ & 0.14 \\
\hline
\end{tabular}

IC: clean intermittent catheterization. 